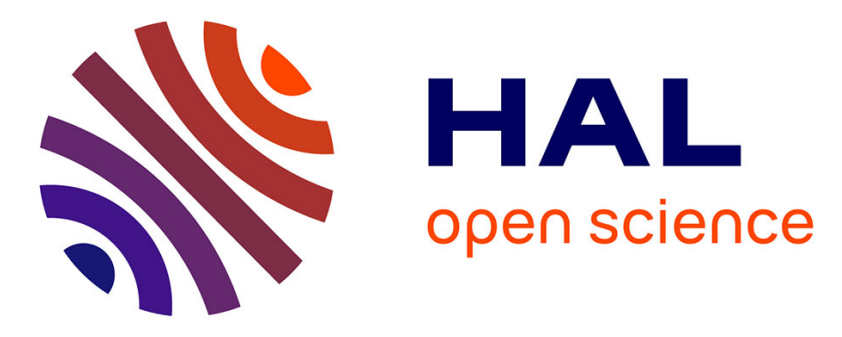

\title{
Elaboration of Architectured Materials by Spark Plasma Sintering
}

\author{
D. Fabregue, Bassem Mouawad, Cyril Buttay, Maher Soueidan, Aude \\ Lamontagne, Romain Forte, Michel Perez, Loic Courtois, Caroline Landron, \\ Eric Maire, et al.
}

\section{To cite this version:}

D. Fabregue, Bassem Mouawad, Cyril Buttay, Maher Soueidan, Aude Lamontagne, et al.. Elaboration of Architectured Materials by Spark Plasma Sintering. THERMEC, Aug 2011, Québec, Canada. pp.1885-1892, 10.4028/www.scientific.net/MSF.706-709.1885 . hal-00687142

\section{HAL Id: hal-00687142 \\ https://hal.science/hal-00687142}

Submitted on 12 Apr 2012

HAL is a multi-disciplinary open access archive for the deposit and dissemination of scientific research documents, whether they are published or not. The documents may come from teaching and research institutions in France or abroad, or from public or private research centers.
L'archive ouverte pluridisciplinaire HAL, est destinée au dépôt et à la diffusion de documents scientifiques de niveau recherche, publiés ou non, émanant des établissements d'enseignement et de recherche français ou étrangers, des laboratoires publics ou privés. 


\title{
Elaboration of architectured materials by spark plasma sintering
}

\author{
FABREGUE Damien ${ }^{1, a}$, MOUAWAD Bassem ${ }^{2, b}$, BUTTAY Cyril ${ }^{2, c}$, SOUEIDAN Maher ${ }^{2, d}$, \\ LAMONTAGNE Aude $^{1, \mathrm{e}}$, FORTE Romain ${ }^{1, \mathrm{f}}$, PEREZ Michel ${ }^{1, \mathrm{~g}}$, COURTOIS Loic ${ }^{1, \mathrm{~h}}$, \\ LANDRON Caroline $^{1, \mathrm{i}}$, MAIRE Eric ${ }^{1, \mathrm{j}}$, MASSARDIER Veronique ${ }^{1, \mathrm{k}}$ \\ ${ }^{1}$ MATEIS INSA Lyon, 25 avenue Jean Capelle, 69621 Villeurbanne, France \\ 2 AMPERE INSA Lyon, 21 Avenue Jean Capelle, 69621 Villeurbanne, France \\ a damien.fabregue@insa-lyon.fr, ${ }^{\mathrm{b}}$ bassem.mouawad@insa-lyon.fr, ${ }^{\mathrm{c}}$ cyril.buttay@insa-lyon.fr, \\ d maher.soueidan@insa-lyon.fr, ${ }^{\mathrm{e}}$ aude.lamontagne@insa-lyon.fr, ${ }^{\mathrm{f}}$ romain.forte@insa-lyon.fr, \\ gmichel.perez@insa-lyon.fr, ${ }^{\mathrm{g}}$ loic.courtois@insa-lyon.fr, ${ }^{\mathrm{i}}$ caroline.landron@insa-lyon.fr, \\ jeric.maire@insa-lyon.fr, $\mathrm{k}^{\mathrm{j}}$ veronique.massardier@insa-lyon.fr
}

Keywords: architectured materials, spark plasma sintering, bonding, porous materials

\begin{abstract}
Spark plasma sintering has been used for decades in order to consolidate a wide variety of materials and permitting to obtain fully dense specimens. This technique has been mainly applied to ceramics. This paper concentrates on an unusual use of spark plasma sintering system: obtaining innovative materials especially architectured ones. Different applications are presented. Firstly, the SPS technique has been used to elaborate nanometers grain size materials or containing nanoscale microstructure. This is possible since the sintering temperature and the holding time are far lower in the SPS compared to other techniques. Then SPS has been used to realize diffusion bonding. In that case again, bonding can be realized at low temperature and for short time. It permits for example to realize bonding between two copper layers which is of a great importance for microelectronic applications. It is worth noting that this bonding can have the same mechanical strength as pure copper even for diffusion time of a few minutes. Secondly, bonding has been also carried out between a metallic layer and a ceramic one. This could lead to design of new layered materials combining interesting properties in terms of mechanical strength but also in terms of electrical resistance. The SPS machine has also been used to obtain porous materials (cobalt alloys or copper) with an adapted microstructure (porosity, tortuosity,). These structures could open new perspectives for biomedical or for microelectronic applications. All these examples lead to a better understanding of the physical processes which happen during spark plasma sintering.
\end{abstract}

\section{Introduction}

Spark plasma sintering is sintering method known from the 50's using DC current in order to heat the sample by joule effect instead of conventional heating method as radiation furnace. It has been shown that using SPS leads to a decrease in the sintering time and temperature compared to other techniques such as HIP or loose sintering [1]. It has been firstly thought that this change of the sintering parameters was due to the presence of plasma between particles permitting not only a cleaning of the surface of the powders but also accelerating the diffusion process between particles. This explanation was questioned especially in the case of non conductive materials such like ceramics. Anyway, recent papers demonstrated the absence of such plasma between particles [2]. But the accelerating sintering (lower sintering temperature and lower sintering time) is definitely 
observed and no other clear explanation has been proposed. This fast sintering process has been then extensively used from years to sinter nanopowders because it permits to avoid extensive grain growing and thus improve mechanical properties or physical properties such as optical transparency [3]. Moreover it also offers the possibility to sinter refractory materials such like metals which are considered as hardly obtainable by others means [4]. Anyway, this technique has been mainly used to obtain fully dense materials from powders trying to tailor the resultant microstructure. It's interesting to note that this technique originally developed for metallic materials has been in the following mainly used on ceramics.

For long times, the materials have been divided into two distinct categories according to their final use: the structural materials and the functional ones. The first ones are assuring the mechanical strength of the structure when the second one are used in order to get a special function such as electrical or thermal conductivity, bio functionalization, etc... However, for years now, efforts have been put to obtain materials that can assure these two functions in order firstly to reduce the costs (for example having at the same time structural and insulation function as the building materials), secondly to reduce the size of the parts (such like in heat exchanger) or to be able to obtain even better properties than the sum of several materials. This has led to the architectured materials where the material(s) are chosen accordingly to the use but also the arrangement of them (morphology of the phases, geometry, etc..). There are different ways to obtain architectured materials: it can be done by in an endogenous way (for example, solidification of a eutectic [5]) or in an exogenous way using smart elaboration paths. This paper is dedicated mainly to the second route where the spark plasma sintering system is used to specifically designing parts that could assure at least two functions, one is obtaining good mechanical strength (or at least sufficient one for the use) and a second one which would be functional. Different examples are presented. Firstly the paper presents the possibility with the SPS system to obtain materials where the microstructure can be tailored. Then real architectured materials are presented by the possibility to assembly materials or by controlling the sintering to get porous materials. The first study shows the possibility to obtain nanostructured materials when the grain size can be tailored such as to assure the mechanical properties desired. Then we will focus on the possibility to realize very efficient diffusion bonding that are quite interesting for microelectronic applications. This has been done on two parts of the same materials as well as on two different materials to get good electrical properties. At last, the SPS has been used to obtain porous materials having interesting properties even for heat exchange or for bio application.

\section{Experimental procedure}

The SPS used is a FCT HPD 25. In each experiment, the pieces or the powders are introduced in a carbon die of $20 \mathrm{~mm}$ inner diameter. SPS process is a pressure assisted, pulsed current, sintering using $\mathrm{ON}-\mathrm{OFF}$ direct current (DC) pulse energizing. The experiments were performed in vacuum $\left(10^{-2}\right.$ Torr) with temperatures ranging from 200 to $1850^{\circ} \mathrm{C}$. The uniaxial force was varied from $5 \mathrm{kN}$ to $24 \mathrm{kN}$ (corresponding to 16 to $76 \mathrm{MPa}$ on the sample respectively) and maintained during the cooling down to room temperature. The temperature was measured on the surface of the graphite die using a thermocouple. The heating rate was varied as well as the holding time according to the type of experiment.

\section{Results}


Elaboration of nanomaterials or containing nanometer reinforcements. This part is firstly dedicated to elaboration of pure iron with a nanometer grain size. In that case, the starting powder is constituted by pure iron $(99,99 \%)$ nanopowders of about $100 \mathrm{~nm}$ diameter obtained by electroexplosion and stabilized in hexane. The thermal cycle used consists in a heating rate of $700^{\circ} \mathrm{C} / \mathrm{min}$ to the desired temperature. The sintering temperature is varied from $550^{\circ} \mathrm{C}$ to $850^{\circ} \mathrm{C}$ and the sintering time is from 1 to 5 minutes. The applied pressure is $80 \mathrm{MPa}$. The challenge here is to produce fully dense sample with nanometer grain size. Fig. 1 presents the final densities obtained with these parameters (sintering time of 1 minute) as well as the resultant hardness measurements. It is worth noticing that the relative densities are very high for such a rapid treatment and one sample has attained a relative density of $100 \%$ when the solvent is evaporated directly in the graphite mold of the SPS machine. Moreover the hardness measurements exhibited by the samples are very high for a pure iron. Looking at the microstructure by TEM on the sample sintered at $700^{\circ} \mathrm{C}$ (Fig. 2) indicates that the grain size has increased a little leading to an average grain size of $250 \mathrm{~nm}$. Using the Hall and Petch relationship with the parameters used for low carbon steel, this gran size is in agreement with the hardness measured.

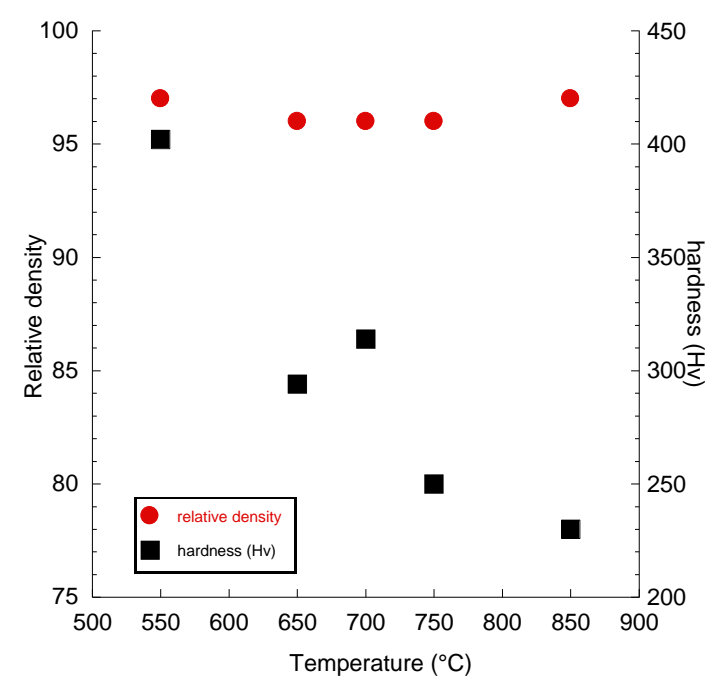

Figure 1: relative density and hardness as a function of the sintering temperature for a sintering time of 1 minute

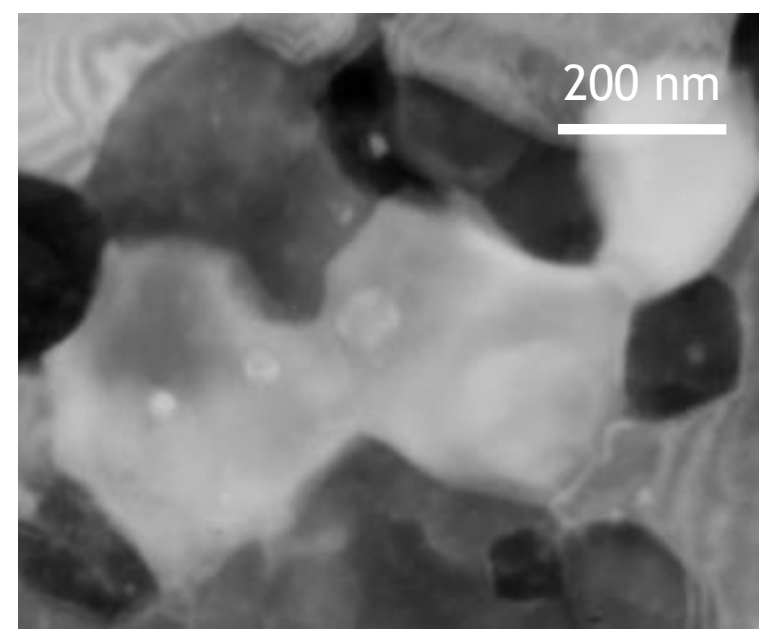

Figure 2: TEM picture of the sample sintered at $700^{\circ} \mathrm{C}$ for 5 minutes 
In that case, the SPS permits to obtain fully dense sample with different grain size resulting in different mechanical strength. The higher the sintering temperature the larger the grains and thus the lower the mechanical strength. It is thus possible to tailor a nanometer grain size material according to the mechanical properties desired.

This technique has also been used to sinter steels strengthened by dispersion of yttria nanooxydes. These steels are known as ODS ferritic steels and are good candidates for generation IV nuclear plants. The main problem for their use is the elaboration process which consists in a lot of steps and leads to a non homogeneous dispersion of the oxydes. Thus SPS has been used to get rid of these drawbacks. The parameters used are a sintering temperature between $850^{\circ} \mathrm{C}$ and $1050^{\circ} \mathrm{C}$, a sintering time of 5 minutes and a pressure applied of $80 \mathrm{MPa}$. Then the maximal final density attained is $98 \%$ which is a satisfactory one since a hot forging process is used afterwards. Moreover a fine precipitation of Yttria oxide is observed in sample right after sintering.

In these cases, the SPS technique has been used to obtain materials with nanometer grain size or with nanometers particles. It has been shown that the microstructure can be tailored according to the desired mechanical properties and that this technique permits to obtain materials difficult to obtain by others ways.

Diffusion bonding. As the spark plasma sintering system permits to decrease the time and the temperature of sintering, it can be thought that the diffusion processes are accelerating in such a technique. Thus the SPS can be a potential system to carry out diffusion bonding. The aim of our study was to explore the possibility of realizing diffusion bonding at low temperature. In effect in the microelectronic applications a lot of links must be created for example between Si chips and heat exchanger parts. In that case, brazing or welding is usually used but it leads to fracture problem when thermal cycling is applied. That's why diffusion bonding is a promising way to link two parts avoiding the brazing process and thus the introduction of an other material with different electrical and thermal properties. For this aim, two copper rod of $29 \mathrm{~mm}$ diameter and $25 \mathrm{~mm}$ length have been put into contact in the SPS after polishing the contact surface. Then the SPS has been used to make the bonding at temperature between $200^{\circ} \mathrm{C}$ and $300^{\circ} \mathrm{C}$ for time varying from 5 to 20 minutes. The heating rate was set to $100^{\circ} \mathrm{C} / \mathrm{min}$ and applied pressure was in the range $16 \mathrm{MPa}$ to $76 \mathrm{MPa}$. Then a tensile sample is machined as shown in Fig 3.

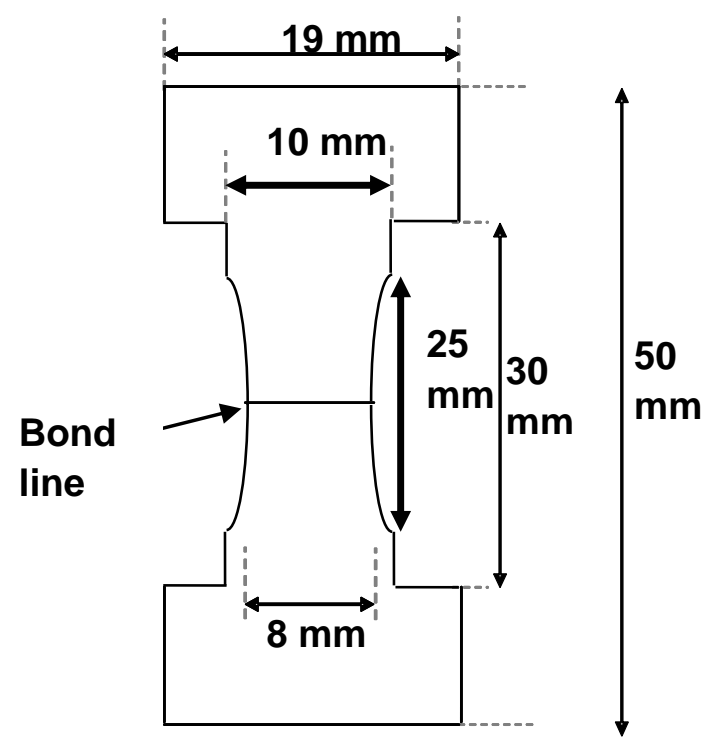

Figure 3: Dimensions of the tensile sample 
Figure 4 shows a typical stress/strain curve obtained.

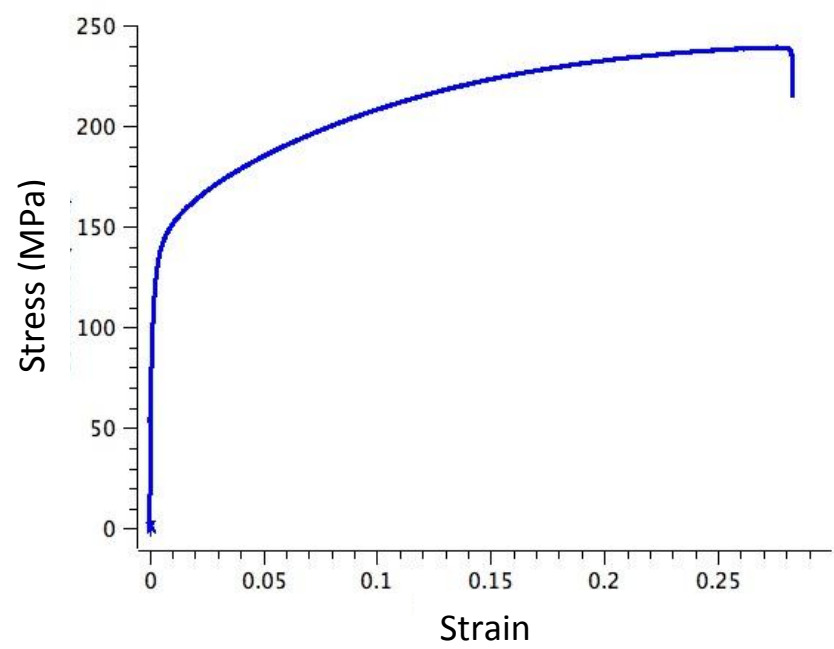

Figure 4: typical stress/strain curve obtained on copper bounded sample

As it can be seen on fig. 4, the sample exhibits a typical behavior for copper with a high ductility a maximal strength of about $250 \mathrm{MPa}$. This leads to the conclusion that the sample has been successfully bonded and that the resultant mechanical properties are close to the pure copper one. This is very interesting since experiments have already been carried out in the literature with usual heating device but the maximal stresses obtained were far from that even for very long time [6]. The maximal stresses obtained are from $120 \mathrm{MPa}$ to more than $300 \mathrm{~Pa}$ depending of the bonding parameters used. Moreover, Figure 5 shows the typical fracture surface exhibiting a lot of dimples characteristics of a very ductile fracture.

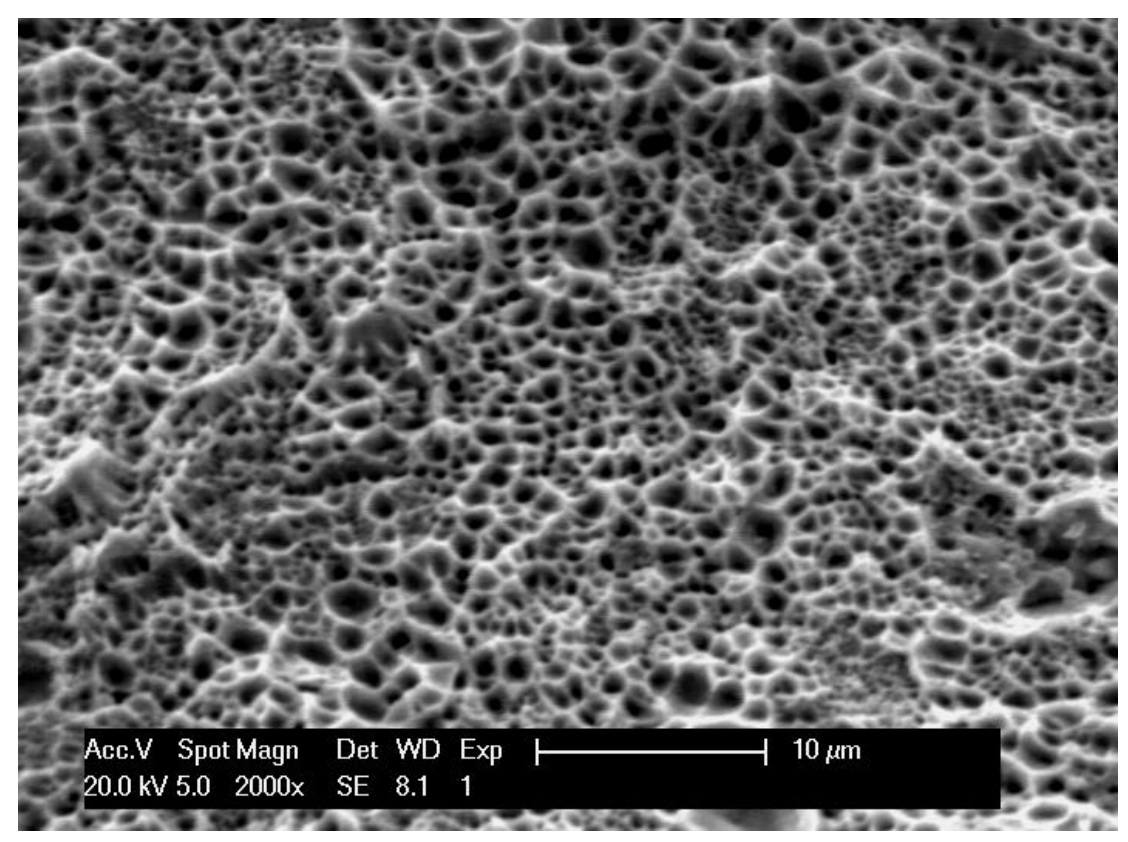

Figure 5: Fracture surface of bonding copper sample

Thus the possibility first to sinter materials and secondly to bond efficiently two materials has been clearly demonstrated. Thus, these two possibilities have been coupled. Molybdenum powder has been sinter at $1850^{\circ} \mathrm{C}$ during 30 minutes and at the same time bonded to a ceramic substrate. Figure 
6 shows the interface between the results of such an experiment where molybdenum powders has been sintered on each face of the substrate.

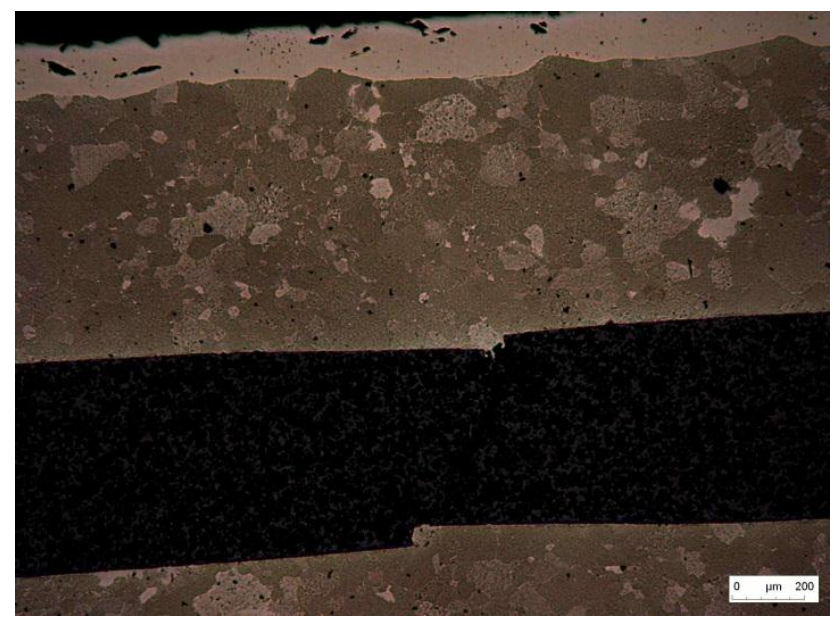

Figure 6 : optical micrograph of the bi material elaborated. The dark is the ceramic substrate, grey is molybdenum and white part is molybdenum carbide.

In that case, molybdenum carbide is formed at the surface of the molybdenum due to carbon diffusion from the piston. But as it can be seen in Fig. 6, the interface between the Mo and the substrate is free from defect. 4 points bending tests will be realized to mechanically characterize the strength of the interface.

Functionally graded materials. The diffusion of carbon observed in the last case, has been used for obtaining a graded material namely steel. A steel powder has been sintered at $1025^{\circ} \mathrm{C}$ during 5 minutes and then rapidly cooled. The concentration in alloying elements is then sufficient to form only martensite in the steel. Then microhardness measurements along the height of the sample have been realized to look at the mechanical properties of the steel produced. Fig. 7 presents the hardness profile obtained in this case.

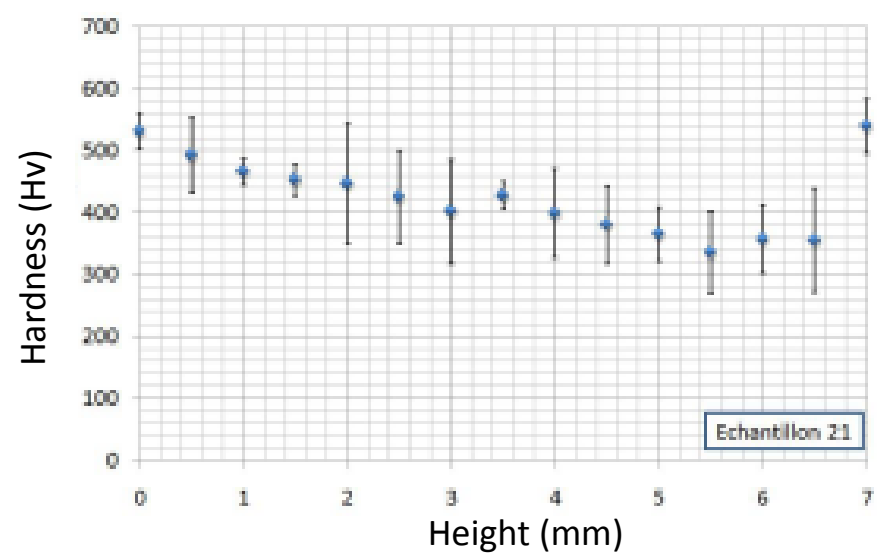

Figure 7: Hardness profile as a function of the height

As it can be seen in Fig.7, the use of the Spark Plasma sintering seems to lead to a gradient in carbon concentration. Firstly, it is clear that the diffusion distances are not in agreement with the usual diffusion distances of carbon in steels. Secondly, the gradient seems to be non-symmetric. It could come from the current flow that could enhance the diffusion in one direction. Others experiments are now in progress to understand what happen in this case. In any case, this possibility 
to obtain functionally graded materials very rapidly compared to other processes by enhanced diffusion, would be of a major interest not only for studying phase transformations but also for structural of functional application where the surface of a part must have different properties from the heart.

Elaboration of porous materials. Porous materials are getting more and more interest for years since they could permit to have good mechanical properties and to gain weight for example. Thus metallic foams have been elaborated for structural applications. Another domain is the heat exchanger where good mechanical properties and possibility to have a flux of liquid inside a material are both needed at the same time. At last, for biomedical applications, porous materials are more and more used to enhance the response of human cells in order to colonize the implants. As we demonstrate the potentialities of the SPS system to control the process of sintering, it has been

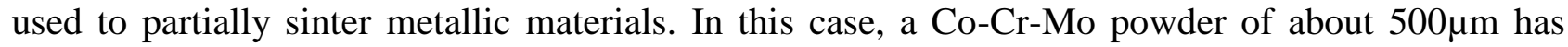
been used. This alloy is known to have very good mechanical properties and to be biocompatible. It has been sintered for different temperatures from 850 to $1050^{\circ} \mathrm{C}$ for 1 minute under different applied pressures (from 0 to $60 \mathrm{MPa}$ ). Then the porous samples have been characterized by $3 \mathrm{D} \mathrm{X}$ ray tomography. Fig. 8 shows the 3D reconstruction of the porous cobalt alloy as well as a $2 \mathrm{D}$ slice showing the arrangement of the spheres.

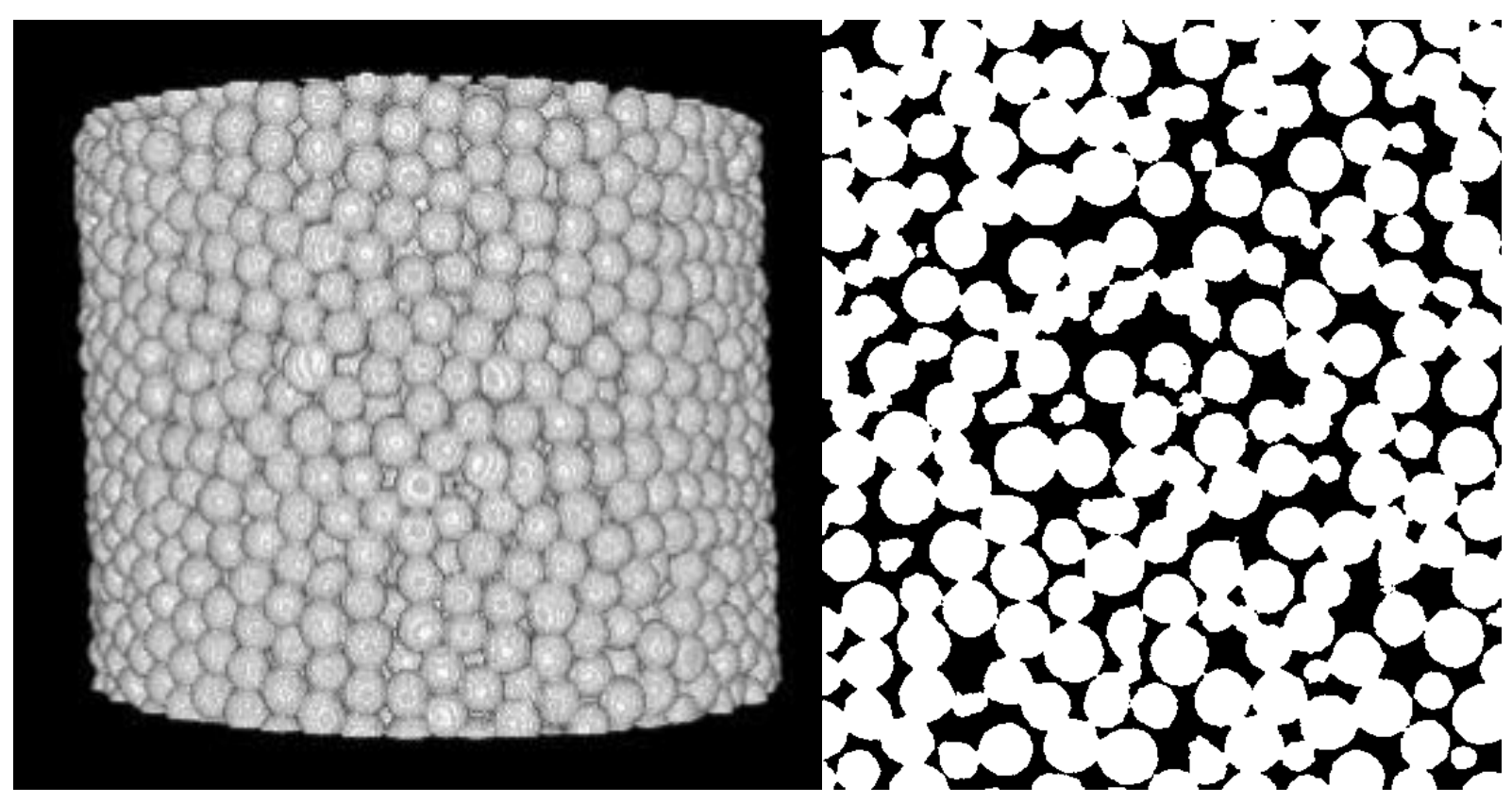

Figure 8: 3D reconstruction of a porous Co-Cr-Mo alloys and a slice of the reconstruction

Thanks to this analysis, it is possible to characterize accurately the influence of the process parameters on the arrangement of the powder and thus to optimize the structure for a given application. Fig. 9 presents the final density as function of the applied pressure. It is shown that the density increases with the pressure as expected. Moreover, the tomography permits to look at the distribution of the gaseous phase (void) and of the solid phase according to the sintering parameters. It is shown that using these parameters for partial sintering, the increase of the temperature does not lead to a change of the size of the solid phase but a small decrease of the size of gaseous phase. That means that the sintering process is limited but rearrangement of the particles is taking place. 

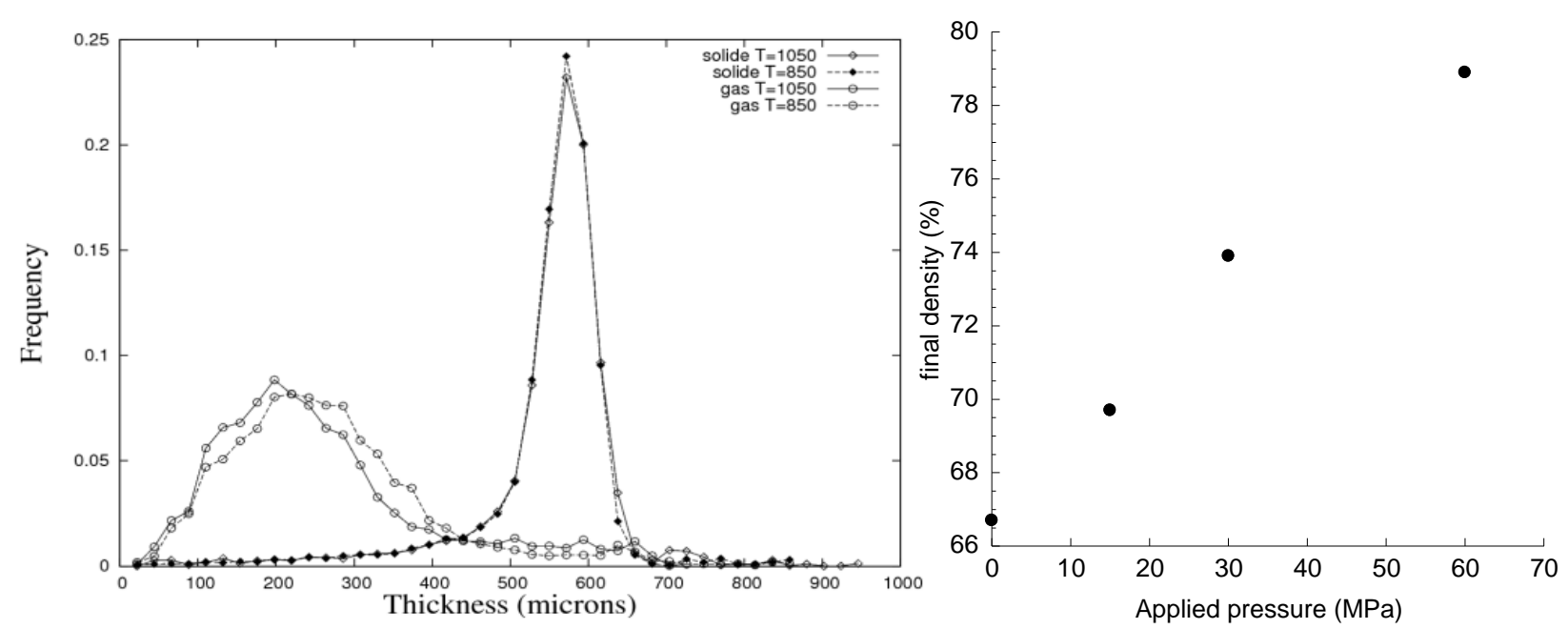

Figure 9: evolution of the final density as a function of the applied pressure and size of two phases as a function of the sintering temperature

Thus SPS technique can be used to partially sinter material to obtain porous parts that could be very interesting when low weight is needed keeping good mechanical properties or for heat exchange or bio medical applications. The SPS thanks to the enhancement of the diffusion process permits to tailor exactly the structure to get the right size of the pores.

\section{Summary}

SPS technique has been demonstrated to have a high potential to product materials according to the application. Firstly it has been shown that it permit to sinter nanopowders very rapidly to keep the initial structure and also to obtain very good diffusion bonding. Thanks to that multilayer materials have been obtained that could have great interest for microelectronic applications. Then functionally graded materials (steel with a carbon gradient) have been produced. At last porous material with a porosity that can be tailored as a function of the applications needs can also be obtained. As a conclusion, SPS process is very promising technique to get architectured materials thanks to it fast and controlled thermal cycle.

\section{References}

[1] : M. Eriksson, Z. Shen, M. Nygren: Powder Metall., vol. 48, n³ (2005), p. 231.

[2]: D.M. Hulbert, A. Anders, J. Andersson, E. J. Laverniaa and A. K. Mukherjee: Scripta Materialia, vol. 60 (2009), p. 835.

[3] I. Alvarez-Clemares, G. Mata-Osoro, A. Fernandez, S Lopez-Esteban, C. Pecharroman, J. Palomares, R. Torrecillas, J.S. Moya : Advanced engineering materials, vol. 12, $\mathrm{n}^{\circ} 11$ (2010) p. 1154.

[4]: R. Ohser-Wiedemann, U. Martin, H.J. Seifert, A. Muller: International journal of refractory metals and hard materials, vol.28, ${ }^{\circ} 4, \mathrm{p} 557$.

[5]: M. Perrut, A. Parisi, S. Akamatsu, S. Bottin-Rousseau, G. Faivre, M. Plapp : Acta Materialia, vl. $58, n^{\circ} 5$, p. 1761.

[6] : J.W. Elmer, J. Klingmann, K. Van Bibber : Physical review special topics, vol.4, 053502 (2001). 